(C) 2020, The Authors. Published by Elsevier Inc. and Fass Inc. on behalf of the American Dairy Science Association ${ }^{\circledR}$. This is an open access article under the CC BY-NC-ND license (http://creativecommons.org/licenses/by-nc-nd/4.0/).

\title{
Evaluating the potential role of tryptophan in calf milk replacers to facilitate weaning
}

\author{
N. Yeste, ${ }^{1} \odot$ A. Bassols, ${ }^{1} \odot$ M. Vidal, ${ }^{2}$ A. Bach, ${ }^{2,3} \odot$ and M. Terré ${ }^{2 *} \odot$ \\ ${ }^{1}$ Department de Bioquímica i Biologia Molecular, Facultat de Veterinària, Universitat Autònoma de Barcelona Cerdanyola del Vallès, 08193 , \\ Barcelona, Spain \\ ${ }^{2}$ Department of Ruminant Production, Institut de Recerca i Tecnologia Agroalimentàries (IRTA), 08140 Caldes de Montbui, Spain \\ ${ }^{3}$ Institució Catalana de Recerca i Estudis Avançats (ICREA), 08010 Barcelona, Spain
}

\begin{abstract}
Tryptophan is a precursor of serotonin, a neurotransmitter that participates in the control of the affective state of an animal. We hypothesized that Trp supplementation could help dairy calves to cope with weaning stress. Twenty-seven Holstein male calves $(48 \pm 0.8 \mathrm{~d}$ old; $82 \pm 2.6 \mathrm{~kg}$ of body weight) were used to evaluate the effects of Trp supplementation at a rate of $4.5 \mathrm{~g} / \mathrm{d}$ via milk replacer (MR) on performance and behavioral parameters around weaning. All calves received the same feeding program $(6 \mathrm{~L} / \mathrm{d}$ at $15 \%$ dry matter from d 1 to $7,4 \mathrm{~L} / \mathrm{d}$ at $15 \%$ dry matter from d 8 to 14 , and $2 \mathrm{~L} / \mathrm{d}$ at $15 \%$ dry matter in one feeding until d 21 of study) and were completely weaned $22 \mathrm{~d}$ after the beginning of the study (around $70 \mathrm{~d}$ of life). Calves were fed a starter feed $(19.3 \%$ crude protein and $16.2 \%$ neutral detergent fiber, on a dry matter basis) and chopped straw ad libitum. Animals were weighed weekly, dry matter intakes were recorded daily, lying behavior was recorded using accelerometers throughout the study, and scan sampling was performed twice a week, $1 \mathrm{~h}$ after the morning feeding, to record behavioral activity (nonnutritive oral behaviors, suckling a neighbor calf, standing, resting, rumination, vocalizations, eating, and drinking). Tryptophan supplementation did not affect calf performance or concentrate and MR intake, but straw intake tended to be greater in nonsupplemented compared with Trp-supplemented calves (153 vs. $129 \pm$ $9.0 \mathrm{~g} / \mathrm{d}$, respectively). Lying time, lying bouts, and lying duration decreased when changes in the MR feeding program occurred, independent of treatment. Similarly, differences in behavioral observations occurred along days of study, with no effect of Trp supplementation. The main changes observed in calf behavior were an increase in vocalizations and standing time $1 \mathrm{~h}$ after the
\end{abstract}

Received December 19, 2019.

Accepted March 23, 2020.

*Corresponding author: marta.terre@irta.cat morning feeding at weaning, but again these changes were independent of treatment. Parameters measured in serum and plasma indicated an increase in Trp, kynurenine, and the kynurenine/Trp ratio after feeding in the Trp calves. A tendency for lower plasma glucose concentration after feeding was observed in the Trp group. No changes in stress markers such as cortisol and haptoglobin in serum were detected. In conclusion, supplementing $4.5 \mathrm{~g} / \mathrm{d}$ of Trp via MR between 48 and $62 \mathrm{~d}$ of life had no effect on performance or behavior in calves around weaning.

Key words: dairy calves, tryptophan, weaning

\section{INTRODUCTION}

The weaning process in most mammalian species (i.e., swine, ruminants) reared in intensive conditions is a stressful event, which may entail a decrease in growth performance (Stamey et al., 2012), an increase in oral stereotypies (nonnutritive oral behaviors, crosssucking) due to the lack of teat-sucking (Horvath and Miller-Cushon, 2017), and suppression of innate immune responses (Hulbert et al., 2011). Offering high planes of nutrition to dairy calves early in life can exacerbate this situation if weaning is not performed properly (Khan et al., 2007) or performed too early (Eckert et al., 2015). Tryptophan is an EAA precursor of serotonin (5-hydroxytryptamine), which has been proposed to help piglets coping with weaning stress, thus improving performance, reducing stress-related hormone serum concentrations, and modulating lying behavior (Shen et al., 2012). An additional biological implication of serotonin, besides modulating anxiety and regulating social behavior and appetite (Gibson, 2018), is the regulation of glucose and lipid metabolism in the peripheral system inducing insulin release in response to glucose and adipogenesis under fed conditions (Yabut et al., 2019). Recently, Hernández-Castellano et al. (2018) supplemented newborn calves with serotonin and reported an increase in mRNA abundance of sev- 
eral immune factors, supporting the role of serotonin in initiating and potentiating the immune response (Yabut et al., 2019).

Based on the benefits of Trp supplementation at the rate of $0.45 \%$ and $0.6 \%$ reported in piglets (Shen et al., 2012; Mao et al., 2014), we hypothesized that Trp supplementation in the milk replacer (MR) may help calves to modulate lying behavior and oral stereotypies at weaning, and potentially improve performance at that stage. Thus, the objective of the present study was to evaluate the effects of supplementing $4.5 \mathrm{~g}$ of $\operatorname{Trp} / \mathrm{d}$ the weeks preceding weaning on calf performance, selected serum analytes, and lying and oral stereotype behaviors.

\section{MATERIALS AND METHODS}

\section{Animals and Feeding Program}

Twenty-seven male Holstein newborn calves (48 \pm $0.8 \mathrm{~d}$ old; $82 \pm 2.6 \mathrm{~kg}$ of $\mathrm{BW}$ ) from a single farm were enrolled in this study between March and June 2018 and raised in the facilities of IRTA at Torre Marimon (Caldes de Montbui, Spain) following an unbalanced but completely randomized design. Calves were managed under common animal management conditions under the supervision of IRTA technicians and the approval of the Animal Care Committee of the Government of Catalonia (authorization code 9733). Before enrollment with Trp supplementation, calves were fed a common diet using the control MR for a period of $10 \mathrm{~d}$.

Table 1. Ingredient and chemical composition (\% DM) of milk replacers ${ }^{1}$

\begin{tabular}{lcc}
\hline Item & CTRL & TRP \\
\hline Ingredient, \% & & \\
Skim milk powder & 39 & 39 \\
Whey protein concentrate 35 & 15 & 15 \\
Whey protein concentrate 60 & 4 & 3.3 \\
50 fatted whey & 39 & 39.2 \\
Premix & 3 & 3 \\
Trp & - & 0.5 \\
Chemical composition, \% DM & & \\
DM & 96.6 & 96.9 \\
CP & 24.1 & 24.0 \\
Fat & 20.5 & 21.8 \\
Lactose & 43.1 & 44.3 \\
Ash & 6.8 & 6.9 \\
\hline
\end{tabular}

${ }^{1} \mathrm{CTRL}=$ calves without amino acid supplementation in the milk replacer; TRP $=$ calves fed a milk replacer with a daily dose of $4.5 \mathrm{~g} / \mathrm{d}$ of Trp.

${ }^{2}$ Vitamin A, 25,000 IU; vitamin $\mathrm{D}_{3}, 4,500 \mathrm{IU}$; vitamin C, $300 \mathrm{mg} /$ $\mathrm{kg}$; vitamin $\mathrm{B}_{1}, 16 \mathrm{mg} / \mathrm{kg}$; vitamin $\mathrm{B}_{2}, 10 \mathrm{mg} / \mathrm{kg}$; vitamin $\mathrm{B}_{6}, 10 \mathrm{mg} /$ $\mathrm{kg}$; vitamin $\mathrm{B}_{12}, 80 \mu \mathrm{g} / \mathrm{kg}$; vitamin $\mathrm{K}_{3}, 5.5 \mathrm{mg} / \mathrm{kg}$; biotin, $160 \mu \mathrm{g} / \mathrm{kg}$; niacin, $50 \mathrm{mg} / \mathrm{kg}$; pantothenic acid, $23 \mathrm{mg} / \mathrm{kg}$; folic acid, $1 \mathrm{mg} / \mathrm{kg} ; \mathrm{Fe}$, $150 \mathrm{mg} / \mathrm{kg} ; \mathrm{Cu}, 10 \mathrm{mg} / \mathrm{kg}$; Zn, $170 \mathrm{mg} / \mathrm{kg} ; \mathrm{Mn}, 40 \mathrm{mg} / \mathrm{kg} ; \mathrm{I}, 1.3 \mathrm{mg} /$ $\mathrm{kg}$; and Se, $0.4 \mathrm{mg} / \mathrm{kg}$.
Calves were individually housed in pens $(1.6 \times 3.2 \mathrm{~m})$ equipped with 3 buckets for water, 2 for concentrate, and 1 for forage. Hutches were bedded with sawdust on a daily basis and calves were bottle-fed MR. For the duration of the trial, calves had ad libitum access to water, chopped barley straw $(3.3 \% \mathrm{CP}, 80.3 \% \mathrm{NDF}$, $54.6 \% \mathrm{ADF}$ on a $\mathrm{DM}$ basis), and pelleted starter feed (19.3\% CP, $16.2 \%$ NDF, $5.8 \%$ ADF, $46.2 \%$ starch, $3.5 \%$ fat on a DM basis). Straw was chopped using a forage chopper (Seco, Curtalo, Italy) to reach the following particle size distribution: $>20 \mathrm{~mm}: 84.9 \%$, between 8 and $20 \mathrm{~mm}: 7.0 \%$, and $<8 \mathrm{~mm}: 8 \%$, according to the Penn State Particle Separator (Heinrichs, 2013). Calves were fed 2 meals (at 0700 and at $1600 \mathrm{~h}$ ) of $3 \mathrm{~L}$ at $15 \%$ MR concentration (total MR intake: $900 \mathrm{~g} / \mathrm{d}$ ) for the first $7 \mathrm{~d}$; subsequently, MR was decreased to $2 \mathrm{~L}$ also at $15 \%(600 \mathrm{~g} / \mathrm{d})$ for the next $7 \mathrm{~d}$, and then MR was limited to a single offer of $2 \mathrm{~L}$ also at $15 \%(300 \mathrm{~g} / \mathrm{d})$ for the next $7 \mathrm{~d}$, when calves were fully weaned at 22 d of study.

\section{Milk Replacer and Treatments}

Calves were randomly assigned to one of the following 2 MR: CTRL $(\mathrm{n}=13)$ without additional Trp supplementation; TRP $(\mathrm{n}=14)$ providing an extra $4.5 \mathrm{~g} / \mathrm{d}$ L-Trp (Livzon Group, Fuxing Pharmaceutical, Ningxia, China) per day (Table 1). Amino acid profiles of MR and starter concentrate are depicted in Table 2 . Calves in the TRP treatment received a fixed amount of Trp. Because the MR offer was decreased throughout the study, the additional Trp required concentration in the MR to reach the daily $4.5 \mathrm{~g}$ was individually added to each bottle before each MR feeding.

\section{Measurements and Chemical Analysis}

Calves were weighed using an electronic weighing scale (Mobba SC-01, Badalona, Spain) at farm arrival and on a weekly basis thereafter. Individual MR and solid feed consumption (pellet and straw) were determined by measuring daily offers and refusals, and then subtracting the leftovers from the offers. Feeds were analyzed for $\mathrm{DM}\left(4 \mathrm{~h}\right.$ at $\left.103^{\circ} \mathrm{C}\right)$, ash $\left(550^{\circ} \mathrm{C}\right.$ calcination), CP with an automatic distiller Kjeldahl (Kjeltec Auto 1030 Analyzer, Tecator) with copper sulfate/selenium as a catalyst instead of copper sulfate/titanium dioxide (method 988.05; AOAC International, 2000), NDF was analyzed using sodium sulfite and heatstable $\alpha$-amylase (Van Soest et al., 1991), ADF was analyzed following Robertson and Van Soest (1981), ether extract following the method 920.39 from AOAC International (1999) with petroleum ether used for distillation instead of diethyl ether (AOAC International, 
2000) with previous acid hydrolysis, and total AA and total tryptophan were determined using fluorescenceHPLC and UV-HPLC, respectively, after a strong acid hydrolyzation with $o$-phthalaldehyde and 9-fluorenylmethoxycarbonyl chloride (UNE-EN-ISO 13903:2005 and UNE-EN-ISO 13904:2005, respectively; UNE, 2005a,b).

At $-4,4,16$, and $23 \mathrm{~d}$ of study, blood samples were obtained from the jugular vein right before and $3 \mathrm{~h}$ after the MR morning feeding and were kept in 10$\mathrm{mL}$ evacuated tubes without anticoagulant to obtain serum for subsequent biochemistry profiles or with lithium heparin for subsequent plasma AA analyses. Serum and plasma were obtained by centrifugation at $1,500 \times g$ for $10 \mathrm{~min}$ at room temperature and stored in aliquots at $-20^{\circ} \mathrm{C}$ until further analysis. Plasma AA were measured by HPLC as described (Yu et al., 2018) with some modifications. Amino acids were derivatized with AccQ Fluor (Waters, Milford, MA) following the instructions provided by the manufacturer. An Elite LaCHrom (Hitachi, Tokyo, Japan) equipped with an UV detector (L-24200, Hitachi) with a Novapak C18 column $(300 \mathrm{~mm} \times 3.9 \mathrm{~mm})$ from Waters were used. The flow rate was $1.0 \mathrm{~mL} / \mathrm{min}$, and the column temperature was kept at $42^{\circ} \mathrm{C}$. The injection volume was $10 \mu \mathrm{L}$ and the detection wavelength was set at $254 \mathrm{~nm}$. The solvent system consisted of 2 eluents: (A) $140 \mathrm{mM}$ sodium acetate trihydrate, $12 \mathrm{mM}$ triethylamine, and 1 mg/L EDTA at pH 5.02 and (B) 60\% acetonitrile/40\% water. The software EZChrom Elite system V3.1.7

Table 2. Amino acid composition of milk replacers and starter concentrate feed

\begin{tabular}{lccc}
\hline & \multicolumn{2}{c}{ Milk replacer $^{1}$} & \\
\cline { 2 - 3 } $\mathrm{AA}, \mathrm{g} / 100 \mathrm{~g}$ & $\mathrm{CTRL}$ & $\mathrm{TRP}$ & \\
\hline Aspartic acid & 2.30 & 2.42 & 1.49 \\
Glutamic acid & 5.37 & 5.72 & 2.89 \\
Serine & 1.27 & 1.37 & 0.78 \\
Histidine & 0.63 & 0.70 & 0.49 \\
Glycine & 0.46 & 0.50 & 0.76 \\
Threonine & 1.49 & 1.47 & 0.61 \\
Arginine & 0.76 & 0.79 & 1.14 \\
Alanine & 1.00 & 1.04 & 0.78 \\
Tyrosine & 0.93 & 1.02 & 0.60 \\
Valine & 1.66 & 1.76 & 0.66 \\
Methionine & 0.55 & 0.61 & 0.26 \\
Phenylalanine & 1.00 & 1.06 & 0.79 \\
Isoleucine & 1.48 & 1.55 & 0.68 \\
Leucine & 2.76 & 2.82 & 1.22 \\
Lysine & 2.08 & 2.13 & 0.81 \\
Hydroxyproline & $<0.040$ & $<0.040$ & 0.14 \\
Proline & 2.11 & 2.21 & 1.00 \\
Tryptophan & 0.35 & 0.83 & 0.20 \\
\hline
\end{tabular}

${ }^{1} \mathrm{CTRL}=$ calves without amino acid supplementation in the milk replacer (Nukamel Productions B.V., Weert, the Netherlands); TRP = calves fed a milk replacer with a daily dose of $4.5 \mathrm{~g} / \mathrm{d}$ of Trp.
(Agilent, Santa Clara, CA) was used for system control and data acquisition.

Serum biochemistry analyses (glucose, urea, triglycerides, cholesterol, creatinine, total proteins, gammaglutamyl transferase, aspartate aminotransferase, and alanine aminotransferase) were determined with OSR reagents (Olympus System Reagent, Beckman Coulter, Hamburg, Germany), free fatty acids (NEFA) were determined with a reagent from Wako (Richmond, VA), antioxidant enzymes superoxide dismutase and glutathione peroxidase $(\mathbf{G P x})$ were determined with Randox reagents (Randox Laboratories Ltd., Crumlin, UK), and haptoglobin was determined by a colorimetric method (Tridelta, Maynooth, County Kildare, Ireland). All determinations were performed with an Olympus AU400 analyzer (Beckman Coulter, Hamburg, Germany).

Cortisol, insulin, and kynurenine were determined by ELISA (salivary cortisol ELISA and insulin ELISA, DRG Diagnostics, Marburg, Germany; L-kynurenine ELISA, Immusmol, Bordeaux, France) according to the manufacturer's instructions. The iEMS Reader MF reader (Thermo Scientific, Waltham, MA) with the Ascent software (version 2.6, Thermo Scientific) was used.

From $2 \mathrm{~d}$ before starting Trp supplementation to 25 d of study, pendant data loggers (Hobo Pendant G Acceleration Data Loggers, Onset Computer Corp., Pocasset, MA) were placed on the right hind leg of each calf using cohesive bandages (Eurimexflex, Divasa Farmavic, Barcelona, Spain) to record position measurements every minute to evaluate calf lying behavior. Data collected for the Hobo data loggers were recovered and processed as described in Yunta et al. (2012) to calculate daily lying time, number of lying bouts per day, and side of recumbency.

Feeding and lying behaviors and oral stereotypies were monitored at $2,4,9,11,16,18,23$, and $25 \mathrm{~d}$ of study for all calves $1 \mathrm{~h}$ after the morning feeding using 5 -min scan sample technique recording the following behaviors: lying, standing, eating solid feed, drinking water, ruminating, nonnutritive oral behaviors (when calves were licking any surface or tongue rolling), suckling the neighbor calves, and vocalizations.

\section{Statistical Analysis}

Performance, lying behavior, and blood data were analyzed using a mixed-effects model accounting for the fixed effects of treatment, time of measurement, and their 2-way interaction, plus the random effect of calf. Time entered the model as a repeated measure using an autoregressive variance-covariance matrix. Initial BW was used as covariate. Blood data were analyzed separately at 0 and $3 \mathrm{~h}$, accounting in the effect 


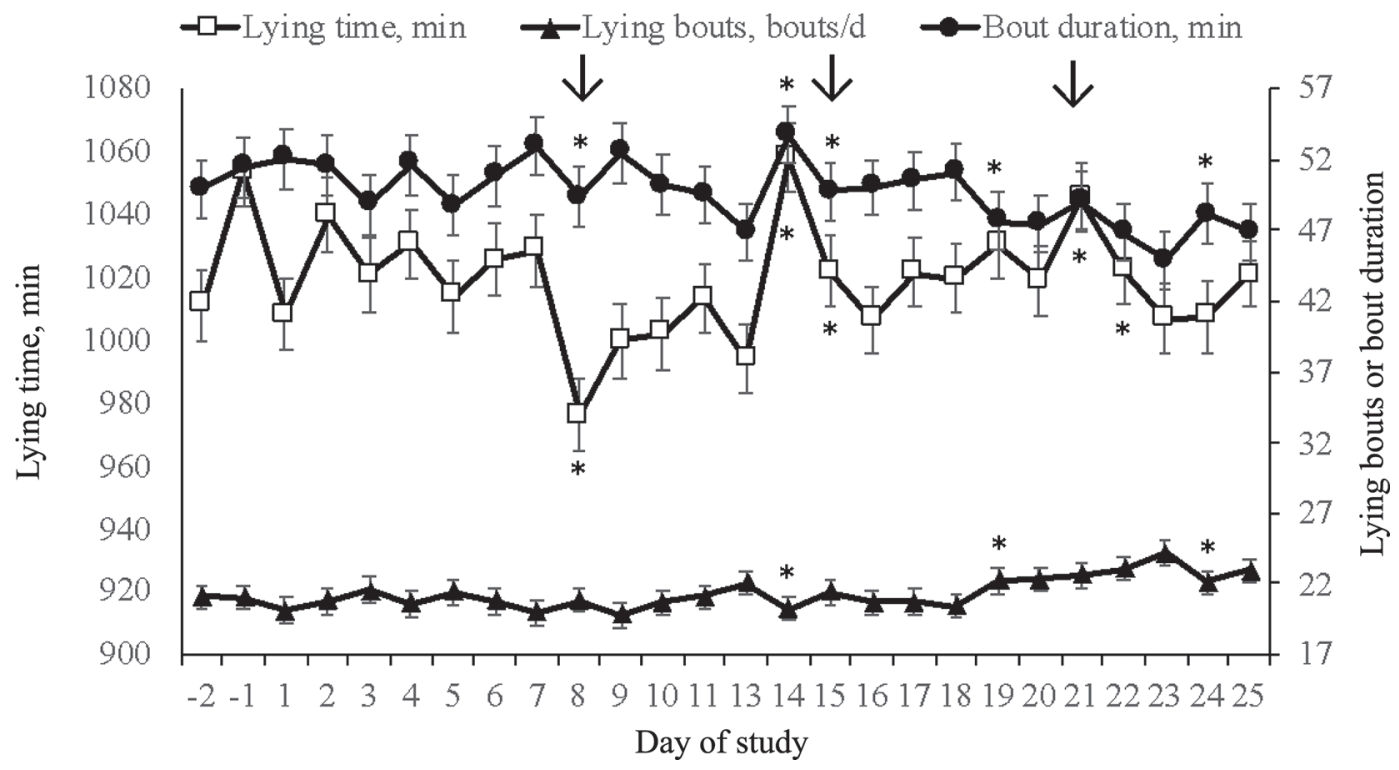

Figure 1. Evolution of lying behavior throughout the study. The arrows denote changes in the milk replacer (MR) feeding program (the first arrow indicates a decrease from $0.9 \mathrm{~kg}$ of $\mathrm{MR} / \mathrm{d}$ to $0.6 \mathrm{~kg}$ of $\mathrm{MR} / \mathrm{d}$, the second denotes a change from 2 feedings of $0.3 \mathrm{~kg}$ to 1 feeding, and the third indicates the weaning day) and the asterisks show differences between days of the study. Error bars are SEM.

of week of sampling using the same model described above. Also, to assess the potential effect of time relative to feeding on blood metabolites, blood data from all weeks were averaged by time relative to feeding, and the same mixed-effects model described above was run using time (hour relative to feeding) instead of week as a repeated measure.

Scan sampling observations were summarized as the number of times each calf performed a given behavior. Data were analyzed with a generalized linear model following a Poisson distribution considering Trp supplementation, the observation day, and their interaction as the fixed effects.

\section{RESULTS AND DISCUSSION}

Tryptophan supplementation did not affect calf performance or concentrate and MR intake, but straw intake tended $(P=0.07)$ to be greater in CTRL compared with TRP calves (153 vs. $129 \pm 9.0 \mathrm{~g} / \mathrm{d}$, respectively). A study conducted with 6 -wk-old pigs reported benefits of L-Trp supplementation improving feed efficiency, in part because of an improvement in nitrogen utilization (Shen et al., 2012), but these benefits were not observed in calves herein. Similar to performance parameters, no differences in lying behavior were observed between MR treatments. However, when changes in the MR feeding program occurred (i.e., reducing MR allowance, number of daily MR feedings, or weaning), lying time, lying bouts, and bout duration decreased (Figure 1). Although Marrero et al. (2019) reported an increase in serotonin bioavailability by feeding $90 \mathrm{mg}$ of 5-hydroxytryptophan (5-HTP)/d to young calves for a period of 10-d, total lying activity was not affected.

Calves in CTRL treatment devoted more time $(P$ $<0.01$ ) to consume concentrate $1 \mathrm{~h}$ after the morning feeding at $11 \mathrm{~d}$, but they devoted less time at $18 \mathrm{~d}$ of study compared with TRP calves (Figure 2A). Calves in the CTRL treatment were observed more $(P<0.05)$ times consuming water $1 \mathrm{~h}$ after the MR morning feeding than TRP calves throughout the study (Figure 2A). More time spent consuming water could indicate that CTRL animals had a greater degree of stress than TRP calves because drinking water has been described as a physiological stress response (Krause et al., 2011). Calves in the TRP treatment spent more time $(P<$ 0.05) lying $1 \mathrm{~h}$ after the morning feeding at $4 \mathrm{~d}$ of study, but time devoted to lying down was similar during the remaining observation days (Figure 2B). After weaning, calves, independent of MR treatment, devoted more time $(P<0.05)$ to ruminate than during the preweaning period, which is a clear consequence of the change in diet (fully dependent on solids) and the consequent need to increase rumination activity. Oral stereotypies did not differ between MR treatments, but vocalizations increased $(P<0.001)$ after weaning (Figure 2C). Vocalizations have been widely used as a noninvasive stress measure (Bolt et al., 2017), but in the present study vocalizations did not differ between MR treatments. In the present study, most of the changes observed in lying time and behavior observations were related to the changes in MR allowance and 
weaning process rather than the Trp supplementation treatment.

Serum biochemistry (Table 3 ) tended to be influenced by MR treatments at $3 \mathrm{~h}$ after the morning MR feeding $(P=0.08)$ with a tendency toward a lower serum glucose concentration in TRP calves after feeding compared with CTRL calves, whereas serum NEFA concentration was greater $(P<0.05)$ before the MR morning feeding in TRP compared with CTRL calves. The lower glucose concentration in TRP calves may be explained because serotonin, a derivative of Trp, has an insulin-releasing effect in fed conditions, and greater levels of insulin in the TRP group would cause a faster uptake of glucose in the peripheral tissues (Yabut et al., 2019). In the present study, insulin levels were similar in both treatments at both sampling times, and this explanation could only be supported by a numerical increase in insulin and insulin to glucose ratio in TRP compared with CTRL calves $3 \mathrm{~h}$ after the morning feeding. The Trp catabolic pathway converts this AA into acetyl-CoA (Kyoto Encyclopedia of Genes and Genomes pathway map00380), a precursor for fatty acid biosynthesis, representing a potential explanation to the increased NEFA plasma concentrations before the MR morning feeding of MR in the TRP group. No other metabolic analytes were altered in plasma, except for a tendency $(P=0.09)$ to decrease GPx activity $3 \mathrm{~h}$ after the morning feeding in the TRP group. Although alterations in other redox markers such as superoxide dismutase were not observed, the decrease in GPx activity might be due to the effect of Trp supplementation in oxidative defenses. Tryptophan 2,3-dioxygenase, a tryptophan-metabolizing enzyme of the kynurenine pathway, has antioxidant activity (Christen et al., 1990), and might have had attenuated GPx antioxidant activity as described in weaned piglets (Mao et al., 2014). Plasma concentration of Trp $3 \mathrm{~h}$ after the morning feeding were greater $(P<0.001)$ in the TRPsupplemented group compared with CTRL animals, indicating that Trp was readily absorbed by the intestine. However, the increase of Trp absorption does not guarantee an increased uptake of Trp by the brain, as it depends on the plasma concentration of Trp in relation to the other large neutral amino acids (LNAA; Höglund et al., 2019). In the present study, similar Trp and LNAA serum concentrations were observed before the morning feeding, but serum Trp concentration and the ratio Trp/LNAA increased in TRP compared with CTRL calves $3 \mathrm{~h}$ after the morning feeding (Table 4), which might have potentiated the uptake of Trp from blood across the brain barrier. In addition to serotonin synthesis, a large majority of dietary Trp is directed toward kynurenine, derived from Trp through the ac- tion of the enzymes indoleamine-2,3-dioxygenase and tryptophan 2,3-dioxygenase (Badawy, 2017). The ratio kynurenine/Trp indicates the metabolic destination of Trp, and changes in this ratio have been linked to brain function and neuroendocrine disorders (Gibson, 2018). In the present study, changes in plasma kynurerine and the kynurenine/Trp ratio were parallel to those in Trp, indicating that Trp metabolic rates were the same in both groups.

Although the increase in time consuming water $1 \mathrm{~h}$ after the morning MR feeding in CTRL calves was related in a previous paragraph to a greater degree of stress in CTRL animals, this hypothesis was not supported by changes in plasma levels of the stress hormone cortisol or haptoglobin, an acute phase protein, which has been also acknowledged as a stress marker (Marco-Ramell et al., 2016). Although no Trp-supplementation effect was observed in stress hormone levels, serum cortisol concentration changed within the weeks and sampling hour of the study, and it was related to the feeding process. Serum cortisol concentrations were greater at the beginning of the study before the morning feeding (Figure 3), suggesting that calves were stressed because of hunger (waiting for the milk feeding). As calves grew up and consumed more concentrate starter feed, serum cortisol levels before feeding decreased (Figure 3). Surprisingly, serum cortisol levels at wk 4 (2 d after weaning) differed between before and after feeding time, but they were lower than serum cortisol concentrations before weaning at $3 \mathrm{~h}$ after feeding. These values suggest that the stress associated with limiting MR allowance seems more acute for young calves than the stress caused by a gradual weaning process. Data regarding the lack of changes in serum haptoglobin concentrations in the present study were in contrast with the results described by Hernández-Castellano et al. (2018), who reported an increase in haptoglobin mRNA levels in blood cells after supplementation of colostrum and milk with $1.5 \mathrm{mg}$ of $5-\mathrm{HTP} / \mathrm{kg}$ of birth weight during the first $15 \mathrm{~d}$ following birth, suggesting an improvement in the immune function in 5-HTP supplemented calves. Hernández-Castellano et al. (2018) used 5-HTP as a serotonin precursor, in contrast to L-Trp, which was used in the present study. This may also explain the divergence in the results, because the enzyme that converts L-Trp to 5-HTP represents a rate-limiting step for serotonin synthesis, and several factors can inhibit this serotonin pathway. In contrast, 5-HTP does not compete with other AA to be absorbed and can easily cross the brain-blood barrier (Birdsall, 1998). Marrero et al. (2019) demonstrated that 5-HTP increased serotonin bioavailability, and probably 5 -HTP is more effective than L-Trp for serotonin synthesis. Therefore, further 
A. Feeding behavior $1 \mathrm{~h}$ after drinking milk replacer

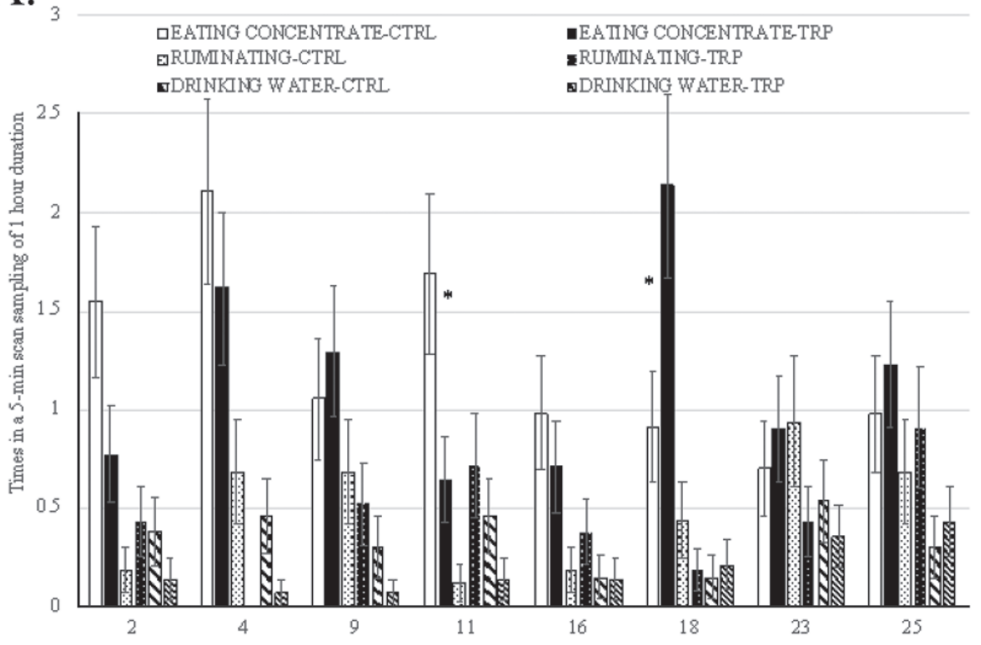

B.

Lying behavior $1 \mathrm{~h}$ after drinking milk replacer

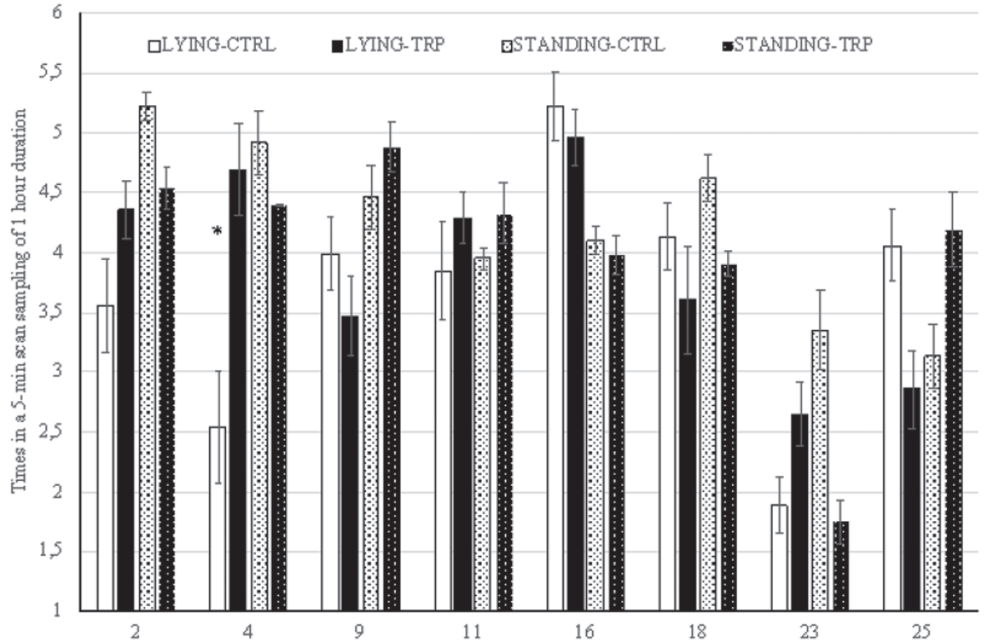

C. Oral stereotypes $1 \mathrm{~h}$ after drinking milk replacer

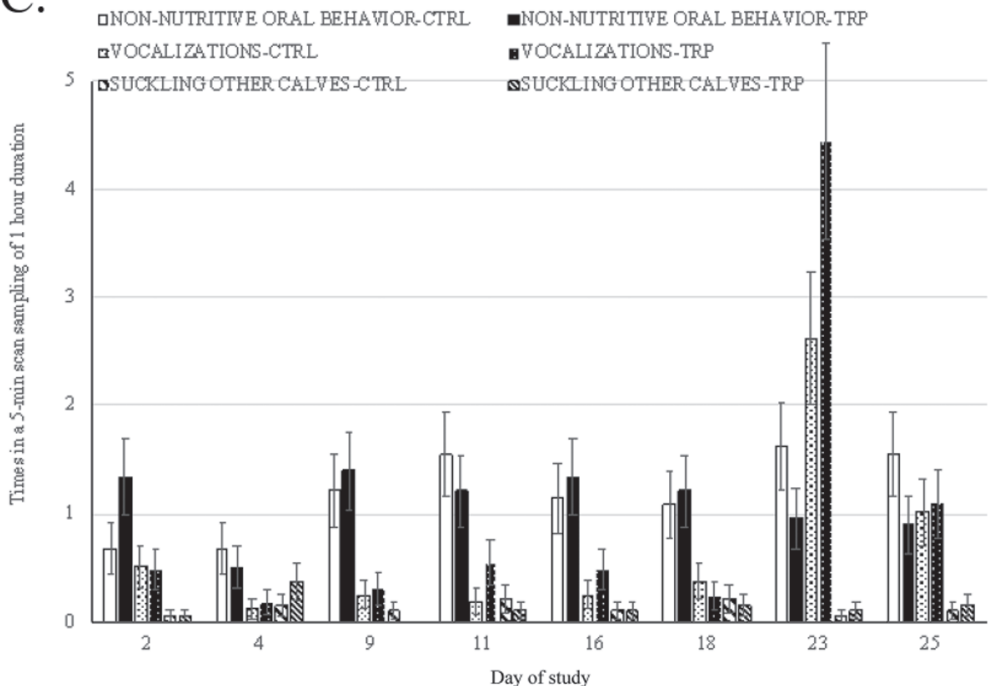

Figure 2. Times of feeding (A) and lying behaviors (B), and oral stereotypies (C) of calves supplemented (TRP) or not (CTRL) with 4.5 $\mathrm{g} / \mathrm{d}$ of Trp $1 \mathrm{~h}$ after the morning milk replacer offer using a 5-min scan technique. Error bars are SEM. 
Table 3. Performance and feed intake of calves as affected by supplementation of $4.5 \mathrm{~g}$ of Trp/d

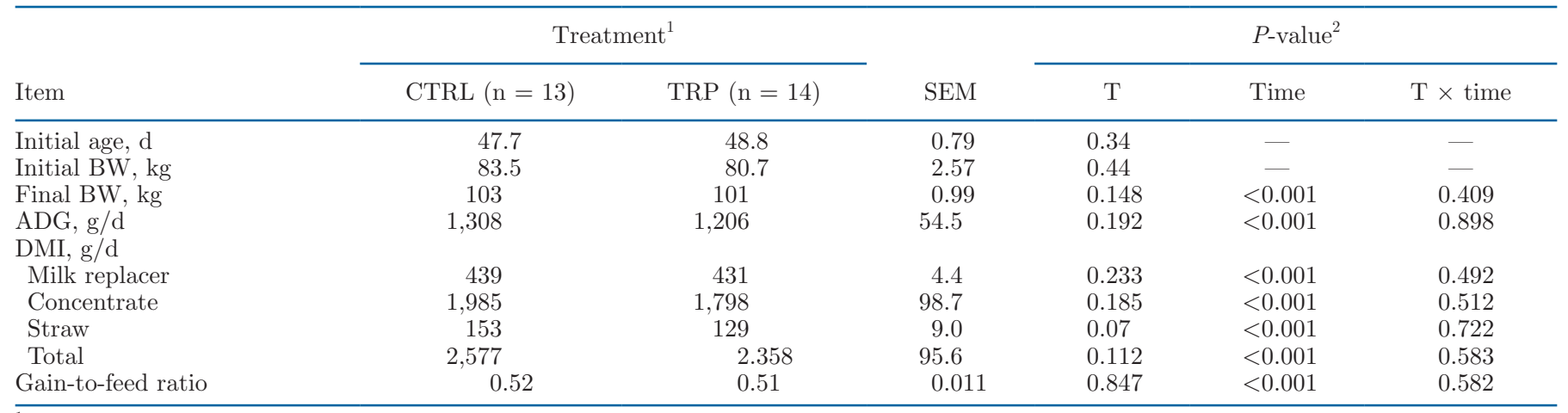

${ }^{1} \mathrm{CTRL}=$ calves without amino acid supplementation in the milk replacer; TRP $=$ calves fed a milk replacer with a daily dose of $4.5 \mathrm{~g} / \mathrm{d}$ of Trp. ${ }^{2} \mathrm{~T}=$ effect of $4.5 \mathrm{~g} / \mathrm{d}$ of Trp supplementation in the milk replacer; time = effect of week of study; $\mathrm{T} \times$ time $=$ effect of the interaction of Trp supplementation with week of study.

studies to evaluate the effects of serotonin on calf behavior are encouraged to use 5-HTP instead of L-Trp to avoid the enzyme-limiting step to transform L-Trp to 5-HTP. Plasma haptoglobin is mainly synthesized in the liver, and Hernández-Castellano et al. (2018) determined the expression of genes coding for haptoglobin in blood cells; thus, differences in the sample site and type of measure may also explain the divergent results between studies.

Last, plasma AA profile was similar in both groups, except for the expected greater levels of Trp at $3 \mathrm{~h}$ after the morning feeding in the TRP group (Table 5). A tendency $(P=0.09)$ for lower plasma Tyr and greater Gly concentration, and lower $(P<0.01)$ plasma Lys

Table 4. Selected serum parameters of calves as affected by supplementation of $4.5 \mathrm{~g}$ of $\mathrm{Trp} / \mathrm{d}$

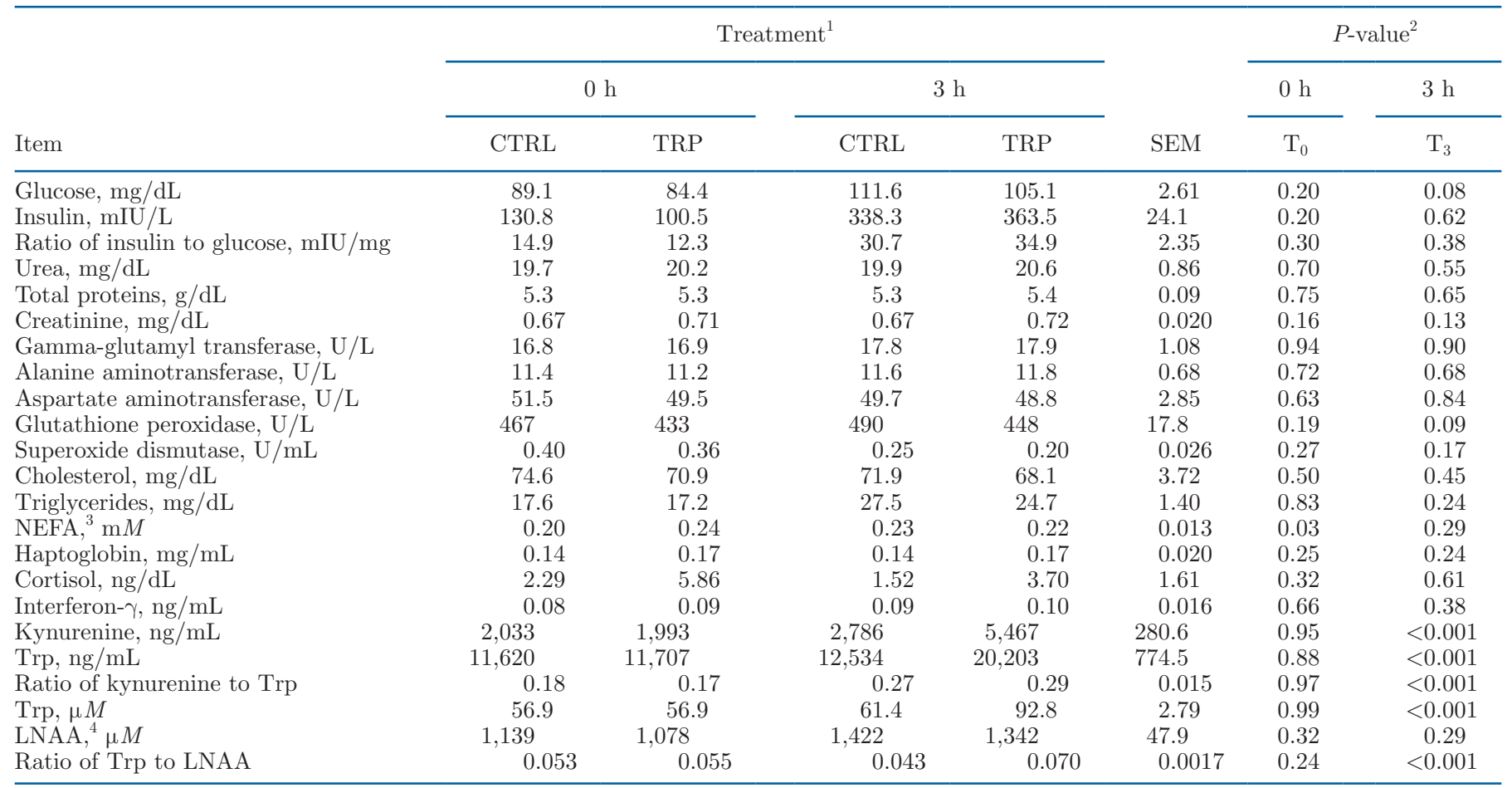

${ }^{1} \mathrm{CTRL}=$ calves without amino acid supplementation in the milk replacer; TRP $=$ calves fed a milk replacer with a daily dose of $4.5 \mathrm{~g} / \mathrm{d}$ of Trp. ${ }^{2} \mathrm{~T}_{0}=$ effect of $4.5 \mathrm{~g} / \mathrm{d}$ of Trp supplementation before the milk replacer morning feeding; $\mathrm{T}_{3}=$ effect of $4.5 \mathrm{~g} / \mathrm{d}$ of Trp supplementation 3 -h after the morning feeding.

${ }^{3} \mathrm{NEFA}=$ nonesterified fatty acids.

${ }^{4}$ LNAA = large neutral amino acids: Val, Ile, Leu, Phe, Tyr, His, Trp, Met, and Thr. 
Table 5. Plasma AA profile of calves as affected by supplementation of $4.5 \mathrm{~g}$ of $\mathrm{Trp} / \mathrm{d}$

\begin{tabular}{|c|c|c|c|c|c|c|c|}
\hline \multirow{2}{*}{$\mathrm{AA}, \mu \mathrm{mol} / 100 \mathrm{~L}$} & \multicolumn{4}{|c|}{ Treatment $^{1}$} & \multirow[b]{2}{*}{ SEM } & \multicolumn{2}{|c|}{$P$-value ${ }^{2}$} \\
\hline & \multicolumn{2}{|c|}{$0 \mathrm{~h}$} & \multicolumn{2}{|c|}{$3 \mathrm{~h}$} & & $\frac{0 \mathrm{~h}}{\mathrm{~T}_{0}}$ & $\frac{3 \mathrm{~h}}{\mathrm{~T}_{3}}$ \\
\hline Asn/Ser & 4.71 & 4.90 & 4.69 & 4.91 & 0.113 & 0.21 & 0.20 \\
\hline Glu & 3.67 & 3.47 & 2.91 & 2.71 & 0.119 & 0.24 & 0.26 \\
\hline Gly & 12.4 & 13.5 & 8.8 & 9.4 & 0.46 & 0.09 & 0.37 \\
\hline Arg & 6.71 & 6.58 & 5.92 & 5.88 & 0.163 & 0.53 & 0.87 \\
\hline Cit & 4.18 & 4.45 & 3.70 & 3.73 & 0.176 & 0.31 & 0.88 \\
\hline Thr & 4.17 & 4.01 & 4.40 & 4.05 & 0.135 & 0.41 & 0.06 \\
\hline Ala & 7.24 & 7.37 & 7.88 & 8.11 & 0.180 & 0.53 & 0.46 \\
\hline Pro & 3.29 & 3.36 & 3.99 & 4.08 & 0.068 & 0.43 & 0.36 \\
\hline Tyr & 2.03 & 1.91 & 1.96 & 1.85 & 0.056 & 0.08 & 0.25 \\
\hline Val & 9.77 & 9.43 & 10.60 & 10.09 & 0.311 & 0.40 & 0.29 \\
\hline Leu & 5.75 & 5.44 & 6.70 & 6.30 & 0.180 & 0.19 & 0.14 \\
\hline Phe & 2.91 & 2.91 & 2.81 & 2.75 & 0.047 & 0.93 & 0.36 \\
\hline Trp & 1.78 & 1.80 & 1.56 & 2.57 & 0.061 & 0.73 & $<0.001$ \\
\hline
\end{tabular}

${ }^{1} \mathrm{CTRL}=$ calves without amino acid supplementation in the milk replacer; TRP = calves fed a milk replacer with a daily dose of $4.5 \mathrm{~g} / \mathrm{d}$ of Trp. ${ }^{2} \mathrm{~T}_{0}=$ effect of $4.5 \mathrm{~g} / \mathrm{d}$ of Trp supplementation before the milk replacer morning feeding; $\mathrm{T}_{3}=$ effect of $4.5 \mathrm{~g} / \mathrm{d}$ of Trp supplementation 3 -h after the morning feeding.

concentration were observed in TRP calves compared with CTRL calves before the morning feeding. After the morning MR feeding, plasma Thr concentration tended $(P=0.06)$ to decrease in TRP compared with CTRL animals.

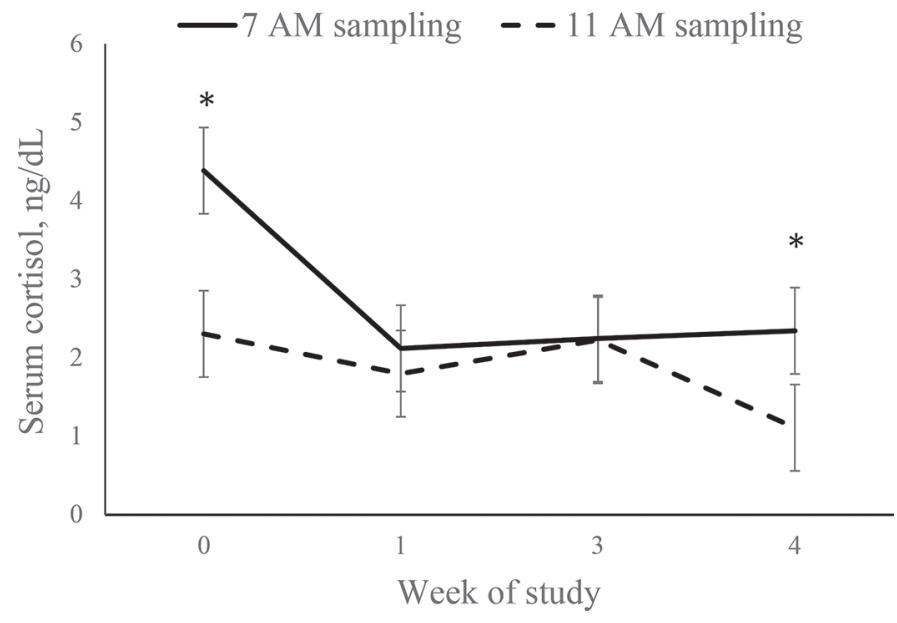

Figure 3. Evolution of serum cortisol concentration throughout the weaning process $[0700 \mathrm{~h}$ sampling corresponds to sampling before the milk replacer (MR) morning feeding, and $1100 \mathrm{~h}$ sampling corresponds to 3 -h after the MR morning feeding at 0,1 , and $3 \mathrm{wk}$ of study]. Asterisks denote differences between 0700 and $1100 \mathrm{~h}$ sampling. Error bars are SEM.

\section{CONCLUSIONS}

Supplementing $4.5 \mathrm{~g} / \mathrm{d}$ Trp via MR between 48 and $62 \mathrm{~d}$ of life did not have any effect on performance and behavior in calves during the weaning process. Modest metabolic changes might suggest some benefits in the Trp uptake or implications in oxidative defenses, but direct positive effects on helping calves coping with the stress associated with limited MR allowance or gradual weaning of young calves were not observed.

\section{ACKNOWLEDGMENTS}

This research was supported by the Spanish Ministry of Economy and Competitivity (AGL2015-68463-C21-P and AGL2015-68463-C2-2-P). A partial support was also received from the Centre de Recerca de Catalunya (CERCA) program from Generalitat de Catalunya (Barcelona, Spain). We also thank Jordi Casino, Clara Jiménez, and Àlex Campreciós from the Institut de Recerca i Tecnologia Agroalimentàries for their help with calf management and care, Granja Murucuc for providing the calves, and Laura Arroyo from Universitat Autònoma of Barcelona (UAB) for collaboration with laboratory analyses. Natalia Yeste is recipient of a fellowship from the Spanish Ministerio de Ciencia, Innovación y Universidades. The authors have no conflicts of interest. 


\section{REFERENCES}

AOAC International. 1999. Official Methods of Analysis. 16th ed. AOAC, Arlington, VA.

AOAC International. 2000. Official Methods of Analysis. 17th ed. AOAC, Arlington, VA.

Badawy, A. A. 2017. Kynurenine pathway of tryptophan metabolism: Regulatory and functional aspects. Int. J. Tryptophan Res. 10:120. https://doi.org/10.1177/1178646917691938.

Birdsall, T. C. 1998. 5-hydroxytryptophan: A clinically-effective serotonin precursor. Altern. Med. Rev. 3:271-280.

Bolt, S. L., N. K. Boyland, D. T. Mlynski, R. James, and D. P. Croft. 2017. Pair housing of dairy calves and age at pairing: Effects on weaning stress, health, production and social networks. PLoS One 12:e0166926. https://doi.org/10.1371/journal.pone.0166926.

Christen, S., E. Peterhans, and R. Stocker. 1990. Antioxidant activities of some tryptophan metabolites: Possible implication for inflammatory diseases. Proc. Natl. Acad. Sci. USA 87:2506-2510. https://doi.org/10.1073/pnas.87.7.2506.

Eckert, E., H. E. Brown, K. E. Leslie, T. J. DeVries, and M. A. Steele. 2015. Weaning age affects growth, feed intake, gastrointestinal development, and behavior in Holstein calves fed an elevated plane of nutrition during the preweaning stage. J. Dairy Sci. 98:6315-6326. https://doi.org/10.3168/jds.2014-9062.

Gibson, E. L. 2018. Tryptophan supplementation and serotonin function: Genetic variations in behavioural effects. Proc. Nutr. Soc. 77:174-188. https://doi.org/10.1017/S0029665117004451.

Heinrichs, J. 2013. The Penn State Particle Separator. Cooperative Extension, College of Agricultural Sciences. DSE 2013-186:1-8.

Hernández-Castellano, L. E., L. L. Özçelik, R. Hernandez, and R. M. Bruckmaier. 2018. Short communication: Supplementation of colostrum and milk with 5-hydroxy-L-tryptophan affects immune factors but not growth performance in newborn calves. J. Dairy Sci. 101:794-800. https://doi.org/10.3168/jds.2017-13501.

Höglund, E., Ø. Øverli, and S. Winberg. 2019. Tryptophan metabolic pathways and brain serotonergic activity: A comparative review. Front. Endocrinol. (Lausanne) 10:158. https://doi.org/10.3389/ fendo.2019.00158.

Horvath, K. C., and E. K. Miller-Cushon. 2017. The effect of milkfeeding method and hay provision on the development of feeding behavior and non-nutritive oral behavior of dairy calves. J. Dairy Sci. 100:3949-3957. https://doi.org/10.3168/jds.2016-12223.

Hulbert, L. E., C. J. Cobb, J. A. Carroll, and M. A. Ballou. 2011. The effects of early weaning on innate immune responses of Holstein calves. J. Dairy Sci. 94:2545-2556. https://doi.org/10.3168/ jds.2010-3983.

Khan, M. A., H. J. Lee, W. S. Lee, H. S. Kim, S. B. Kim, K. S. Ki, J. K. Ha, H. G. Lee, and Y. J. Choi. 2007. Pre- and postweaning performance of Holstein female calves fed milk through step-down and conventional methods. J. Dairy Sci. 90:876-885. https://doi .org/10.3168/jds.S0022-0302(07)71571-0.

Krause, E. G., A. D. de Kloet, J. N. Flak, M. D. Smeltzer, M. B. Solomon, N. K. Evanson, S. C. Woods, R. R. Sakai, and J. P. Herman. 2011. Hydration state controls stress responsiveness and social behaviors. J. Neurosci. 31:5470-5476. https://doi.org/10 $.1523 /$ JNEUROSCI.6078-10.2011.
Mao, X., M. Lv, B. Yu, J. He, P. Zheng, J. Yu, Q. Wang, and D. Chen. 2014. The effect of dietary tryptophan levels on oxidative stress of liver induced by diquat in weaned piglets. J. Anim. Sci. Biotechnol. 5:49. https://doi.org/10.1186/2049-1891-5-49.

Marco-Ramell, A., A. M. De Almeida, S. Cristobal, P. Rodrigues, P. Roncada, and A. Bassols. 2016. Proteomics and the search for welfare and stress biomarkers in animal production in the onehealth context. Mol. Biosyst. 12:2024-2035. https://doi.org/10 .1039/C5MB00788G.

Marrero, M. G., B. Dado.Senn, S. L. Field, D. R. da Silva, A. L. Skibiel, and J. Laporta. 2019. Increasing serotonin bioavailability in preweaned dairy calves impacts hematology, growth, and behavior. Domest. Anim. Endocrinol. 69:42-50. https://doi.org/10.1016/j .domaniend.2019.04.007.

Robertson, J. B., and P. J. Van Soest. 1981. The detergent system of analysis. Chapter 9, pages 123-158 in The Analysis of Dietary Fiber in Food. W. P. T. James and O. Theander, ed. Marcel Dekker, New York, NY

Shen, Y. B., G. Voilqué, J. D. Kim, J. Odle, and S. W. Kim. 2012. Effects of increasing tryptophan intake on growth and physiological changes in nursery pigs. J. Anim. Sci. 90:2264-2275. https://doi .org/10.2527/jas.2011-4203.

Stamey, J. A., N. A. Janovick, A. F. Kertz, and J. K. Drackley. 2012. Influence of starter protein content on growth of dairy calves in an enhanced early nutrition program. J. Dairy Sci. 95:3327-3336. https://doi.org/10.3168/jds.2011-5107.

UNE. 2005a. Animal feeding stuffs. Determination of amino acids content. ISO13903:2005. UNE, Madrid, Spain.

UNE. 2005b. Animal feeding stuffs. Determination of tryptophan content. ISO13904:2005. UNE, Madrid, Spain.

Van Soest, P. J., J. B. Robertson, and B. A. Lewis. 1991. Methods for dietary fiber, neutral detergent fiber, and nonstarch polysaccharides in relation to animal nutrition. J. Dairy Sci. 74:3583-3597. https://doi.org/10.3168/jds.S0022-0302(91)78551-2.

Yabut, J. M., J. D. Crane, A. E. Green, D. J. Keating, W. I. Khan, and G. R. Steinberg. 2019. Emerging roles for serotonin in regulating metabolism: New implications for an ancient molecule. Endocr. Rev. 40:1092-1107. https://doi.org/10.1210/er.2018-00283.

Yu, K., M. Matzapetakis, D. Valent, Y. Saco, A. M. De Almeida, M. Terré, and A. Bassols. 2018. Skeletal muscle metabolomics and blood biochemistry analysis reveal metabolic changes associated with dietary amino acid supplementation in dairy calves. Sci. Rep. 8:13850. https://doi.org/10.1038/s41598-018-32241-4.

Yunta, C., I. Guasch, and A. Bach. 2012. Short communication: Lying behavior of lactating dairy cows is influenced by lameness especially around feeding time. J. Dairy Sci. 95:6546-6549. https://doi .org/10.3168/jds.2012-5670.

\section{ORCIDS}

N. Yeste @ https://orcid.org/0000-0003-2471-2064

A. Bassols (ㄴ) https://orcid.org/0000-0003-4213-2274

A. Bach ๑ https://orcid.org/0000-0001-6804-2002

M. Terré $\odot$ https://orcid.org/0000-0002-2815-9035 